\title{
Consumers' Cognitive, Emotional and Behavioral Responses towards Background Music: An EEG Study
}

\author{
Athanasios Gkaintatzis ${ }^{1}$, Rob van der Lubbe ${ }^{2}$, Kalipso Karantinou ${ }^{1}$ and Efthymios Constantinides ${ }^{2}$ \\ ${ }^{1}$ Department of Marketing and Communication, Athens University of Economics and Business, \\ Patision Street 76, Athens, Greece \\ ${ }^{2}$ Faculty of Behavioural, Management and Social Sciences (BMS), University of Twente, \\ Drienerlolaan 5, Enschede, Netherlands
}

Keywords: Neuromarketing, Electroencephalogram (EEG), Consumer Behavior.

\begin{abstract}
The physical environment affects individuals emotionally, behaviorally and cognitively. Servicescapes or atmospherics studies the effect of environmental stimulation to consumers. Environmental stimuli affect consumers' attention and cause them emotions such as pleasure and arousal; those emotional responses affect in turn consumers' behavioral responses such us approach and avoidance tendencies towards the environment. Hence, the level of arousal-nonarousal and the pleasure-displeasure experienced by a consumer along with other intervening variables such as momentary mood and stimulus screening ability will determine his/her approach-avoidance responses towards the environmental stimuli. The paper studies atmospherics with neuromarketing and conventional marketing research methods: Specifically, using electroencephalography (EEG) and surveys, it focuses on the effect of background music on Consumer's arousal, pleasure, attention and approach/avoidance tendencies. The results are expected to have significant academic relevance both for the servicescapes / atmospherics and the neuromarketing / consumer neuroscience research streams of literature and also managerial implications.
\end{abstract}

\section{INTRODUCTION}

This paper investigates atmospherics with neuromarketing methods. Servicescapes or atmospherics is a subfield of marketing which applies environmental psychology to marketing research in studying the effects of the environment to consumers within it (Kotler, 1973; Bitner, 1992). Neuromarketing or Consumer Neuroscience applies neuroscience to marketing research and studies consumers' emotional, behavioral and cognitive responses (Turley and Milliman, 2000; Mattila and Wirtz, 2001).

\section{LITERATURE REVIEW}

Music has long been considered an efficient and effective means for triggering moods and communicating nonverbally (Bruner, 1990). It is capable of evoking complex and affective behavioral responses in consumers. Specifically, music affects consumer behavior in retail environments (Milliman,
1982, Milliman, 1986; Yalch and Spangenberg, 1990) and influences their desire to affiliate in buyer-seller interactions (Dube', Chebat and Morin, 1995). Appropriately structured music acts on the nervous system as a key on a lock, activating the brain with corresponding emotional reactions (Clynes and Netheim, 1982) and also plays an important role among higher brain functions (Bhattacharya, Petsche and Pereda, 2001). It is therefore not surprising that music has become a major subject of consumer research, both at the point of purchase and in advertising (Bruner, 1990).

Previous research has been focused on specific elements of music such as volume, pitch, tempo, and rhythm are manipulated. Regarding tempo, Bruner (1990) argues that slow tempo music reduces anxiety, whereas faster tempo music is associated with increased worry and emotionality. In this respect, faster tempo music was associated with positive affective states such as happiness and excitement, whereas slow tempo music was associated with feelings of sadness (Bruner, 1990). Milliman proposed that consumers spent more time and money in environments with slow-tempo music

Gkaintatzis, A., van der Lubbe, R., Karantinou, K. and Constantinides, E. 
and took more time to eat their meals compared to those in the fast-music condition (Milliman, 1982; Milliman, 1986). Following Milliman, Vanderark and Ely (1993) reported that high tempo and high rhythmic content in the music led to an increase in physiological arousal among consumers (Mattila and Wirtz, 2001). Dube' et al., (1995) proposed that music-induced pleasure and arousal might have independent effects on consumers' desire to affiliate in a buyer-seller interaction, with more desire to affiliate associated with more pleasure and more arousal. Even though there is ample extant research on the effect of music on consumer behavior, there are still many conflicting findings and inconclusive results, posing an academic and managerial challenge. Furthermore, music has been extensively studied in the marketing literature using traditional research methods. Little is however known about the mental processes that underpin certain consumer behaviors and the buying process. We aim to redress such shortcoming by employing neuromarketing methods that have the capacity to yield more precise and objective results. In this study we will investigate the effects of background music on consumer behavior using a tool from the Neuroscience domain namely Electroencephalography (EEG) in combination with classic questionnaires.

\section{EXPERIMENTAL DESIGN}

On the basis of the above mentioned approach, the purpose of this study is to manipulate the tempo and specifically the Beats Per Minute (BPM) of music while keeping all the other elements of music unchanged during the consumer decision-making process, and examine how the consumer behavior is affected. By manipulating BPM, different servicescapes or to be more precise musicscapes, can be created. Musicscapes display significant relationships between specific musical variables and desired consumer behavioral outcomes (Oakes, 2000). According to the literature, 80 or lower BPM is considered as slow tempo musicscape, between 80 and 120 is considered as moderate and 120 or more is considered as fast tempo musicscpae (Milliman, 1986; Kellaris and Kent, 1993; Bruner, 1990; Edworthy and Waring, 2006). In this experiment, there will be three different such conditions: a 70 BPM, a 120 BPM and a 170 BPM condition. Nonvocal music is chosen, because we want to focus on the effect of music on consumer behavior; not on the effect of linguistics. Specifically, a violin piece is chosen, because it can reach high BPM without producing noise in the ears of the listener and it is also coherent with the product selecting task; the product in question is bolted wine.

Participants will be asked to perform a task while being exposed to the three different musicscapes conditions in random order. They will have to make a binary choice between bottles of wine, one presented in the right side of the computer screen and one presented in the left. The side that each bottle will be presented will be random. This task is chosen, because we want to replicate a hedonic servicescape. Hedonic services are those that provide consumers with values such as excitement, playfulness and entertainment and according to the literature, arousal has a bigger effect on pleasure and satisfaction in hedonic servicescapes than in utilitarian servicescapes (Babin, Darden and Griffin, 1994).

Great effort will be made to keep all other conditions such as temperature, air quality, humidity and cleanliness constant and similar for all participants. A pretest will also be conducted to adjust the volume of the music. In addition, feedback from the pretest sample is expected to help with the wording of the questions and the questionnaire layout.

\section{METHODS}

\subsection{Electroencephalography (EEG)}

Electroencephalography (EEG) is a non-invasive medical imaging technique that records the extracellular electrical activity of the brain, generated by the action potentials of neurons (Abhang, Gawali, and Mehrotra, 2016; Alix, Ponnusamy, Pilling and Hart, 2017) and it is a widely used method in consumer neuroscience. EEG is chosen as a research method, because it has advantages such high-tempoal resolution (Abhang et al., 2016; Cohen, 2014; Michel and Murray, 2012; Ramsøy, 2014), and can capture fast, dynamic, time sequenced cognitive events (Cohen, 2014); next to that is a relatively low-cost neuromarketing technique. Furthermore, EEG is capable of measuring visual attention, which is one of the main purposes of this study.

In order the EEG measurements to be done, two computers will be used: one for presentation and one for recording, both of them connected with the BrainVision ActiPower Amplifier. BrainVision Recorder and BrainVision Analyzer will be used in 
order to collect the data and analyze them Participants will be sited in a comfortable chair 60 $\mathrm{cm}$ away from the presentation computer. The EEG will be recorded continuously from 32 active $\mathrm{Ag} / \mathrm{AgCl}$ electrode sites: AFz, AF3, AF4, AF7, AF8, F1, F2, F5, F6, FCz, FC3, FC4, FT7, FT8, C3, C4, C5, C6, CPz, CP3, CP4, TP7, TP8, P1, P2, P5, P6, $\mathrm{POz}, \mathrm{PO} 3, \mathrm{PO} 4, \mathrm{PO} 7$, and $\mathrm{PO} 8$ using an EasyCap62 channel cap with standard international 10-20 system layout. The occulograms (EOG) will be also recorded continuously from 5 electrodes attached around the eyes of the participants.

Regarding the EEG analysis, special focus will be paid to the Posterior-Contralateral Negativity (PCN), which is an Event-Related-Potential (ERP) and an Event-Related-Lateralization (ERL) measure. Evoked potentials (EPs) and event-related potentials (ERPs) are components of the EEG that arise in response to different kinds of stimuli, such as auditory, gustatory, olfactory, somatosensory and visual input (Ramsøy, 2014). ERPs can be transformed into ERLs by calculating the contraipsilated hemispherical difference for the relevant electrodes (Van der Lubbe and Utzerath, 2013).

Parameters of the Posterior-Contralateral Negativity (PCN), also known as the N2-posterior contralateral (N2pc), will be analyzed in order to assess if a certain bottle of wine caught participants' visual attention. The PCN expresses an increased negativity in the visual area (posterior electrodes) contralateral to the stimulus position in a time window of approximately 175 and $300 \mathrm{~ms}$ (or even less) after the stimulus presentation (Tollner, Muller and Zehetleitner, 2011a; Tollner, Zehetleitner, Gramann, and Muller, 2011b; Vossel, Geng and Friston, 2015). The PCN measurement can be used to indicate visual attention (Van der Lubbe, Jaśkowski, Wauschkuhn, \& Verleger, 2001).

Based on the assumption that PCN reflects the visual allocation of attention based on perceptual stimulus properties; the present study aims at showing that PCN parameters can be used to assess and predict consumers' preferences for a specific product on the base of external cues, in the case at hand different bottles of wine. It is expected that individual visual attention for a specific wine label are reflected by EEG lateralization in the parieto-occipital area (PO8/PO7 electrode pair. Therefore, it is hypothesized that:

H1: A negative-going deflection (PCN) is indicative of participants' preferences for a bottle of wine.

Falkenstein, Hohnsbein and Hoormann (1994) examined the influence of time pressure in a choicereaction task with visual and auditory stimuli in which time pressure was manipulated. They focused on the ERP component P3 latency, which reflects processes involved in decision making and stimulus evaluation. In this study pressure to the participants will be induced by manipulating music's BPM. It is expected that an increase in BPM of music will lead to an increase in participants' reported stress and a decrease in time needed to finish the task. Therefore, it is hypothesized that:

H2: P3 latency is also expected to be affected by time pressure.

The balance between activity in the left and right frontal cortex, commonly referred to as asymmetric frontal cortical activity, has served as a proxy for an organism's motivational direction (i.e., approach vs. avoidance) (Kelley, Hortensius, Schutter, HarmonJones, 2017). According to the literature, greater relative left (right) frontal cortical activity is associated with approach (avoidance) motivation.

H3: Greater relative left frontal cortical activity is associated with approach tendency of the participant towards the medium tempo music. Greater relative right frontal cortical activity is associated with avoidance tendency of the participant towards the extreme fast or extreme slow music.

\subsection{Survey}

After each music condition, participants will have to answer a survey in order to measure their emotional responses: pleasure and arousal (with 7 items and 7point likert scale from Mehrabian and Russel, 1974), their cognitive responses: attention (with 5 items and 7-point likert scale from Brown and Ryan, 2003) and satisfaction from background music (with 9 items and 7-point likert scale from Oliver and Swan, 1989), and their behavioral responses: approach/avoidance tendencies (8 items, 7-point likert scale from Donovan and Rossiter, 1982)

It is expected that people prefer moderate arousal level over extreme high or low when they do a task. The hypotheses that will be tested is the following:

H4: While making a binary choice, listening to 120 BPM music piece is pleasant, satisfactory and leads to approach tendency towards the environment. Extreme fast or extreme slow music is unpleasant, unsatisfactory and leads to avoidance behavior towards the environment.

The faster response and more stressful is expected to be in the 170 BPM music condition and the slower response and less stressful in the $70 \mathrm{BPM}$ music condition. Therefore, it is hypothesized that: 
H5: An increase in BPM of music will lead to an increase in participants' reported stress and a decrease in time needed to finish the task.

The faster the music, the more difficult it is expected to be to complete the task. The last hypothesis will be that:

H6: While the BPM of music are increasing participant's attention is decreasing.

\section{DATA PROCESSING AND EXPECTED RESULTS}

Following the hypotheses, attention is expected to decrease and stress to increase, while BPM of music are increasing. Arousal and heart rate is expected to increase while BPM of music are increasing. It is also expected that moderate arousal level induced from the 120 BPM violin piece is pleasant and satisfactory, leading to approach behavior; in parallel, extreme high and extreme low arousal level induced from 70 and 170 violin pieces is not pleasant and satisfactory, leading to avoidance behavior. In addition, the faster response and more stressful is expected to be in the $170 \mathrm{BPM}$ music condition and the slower in the 70 BPM music condition.

At the end of the study a final conclusion will be drawn based on the results. The relative advantages and disadvantages of survey and EEG and their potential complementarity will be critically evaluated. Academic and managerial implications are also expected to come out, enabling better utilization of music in consumer research and practice when dealing with customer behavior. Further research in this domain could be done by including more neuromarketing techniques such as Functional Near-Infrared Spectroscopy (fNIRS).

\section{REFERENCES}

Abhang, P. A, B. W. Gawali, and S. C. Mehrotra (2016). Introduction to EEG-and speech-based emotion recognition. Academic Press.

Alix, J. J. P., A. Ponnusamy, E. Pilling, and A. R. Hart (2017). "An introduction to neonatal EEG". In: Paediatrics and Child Health 27.3, pp. 135-142.

Annett, M. (1970). "A classification of hand preference by association analysis". In: British Journal of Psychology 61.(3), pp. 303-321.

Babin BJ, Darden WR, Griffin M. Work and/or fun: measuring hedonic and utilitarian shopping value. J Consum Res 1994;20:644-56 [March].
Bach, M. (1996). The Freiburg Visual Acuity Test???Automatic Measurement of Visual Acuity. Optometry and Vision Science, 73(1), 49-53.

Baker, J. (1987), The role of the environment in marketing services: the consumer perspective In J. Czepiel, C. A. Congram, \& J. Shanahan, eds. The Services Challenge: Integrating for Competitive Advantage. Chicago: American Marketing Association, pp.79-84.

Bhattacharya, J., Petsche, H., \& Pereda, E. (2001). LongRange Synchrony in the $\gamma$ Band: Role in Music Perception. The Journal of Neuroscience, 21(16), 6329-6337.

Bitner, M.J., "Servicescapes: The Impact of Physical Surroundings on Customers and Employees," Journal of Marketing, vol. 56, no. 2, 1992, p. 67

Brown, K.W. \& Ryan, R.M. (2003). The benefits of being present: Mindfulness and its role in psychological well-being. Journal of Personality and Social Psychology, 84, 822-848.

Bruner, G. C. (1990). Music, mood, and marketing. Journal of Marketing, 54(4), 94-104.

Clynes M., Nettheim N. (1982) The Living Quality of Music. In: Clynes M. (eds) Music, Mind, and Brain. Springer, Boston, MA

Cohen,M.X.(2014).Analyzingneuraltimeseriesdata:theorya ndpractice. MIT Press.

Donovan, Robert and John Rossiter (1982), "Store Atmosphere: An Environmental Psychology Approach," Journal of Retailing, 58 (Spring), 34-57.

Dubé, L., Chebat, J.-C., \& Morin, S. (1995). The effects of background music on consumers' desire to affiliate in buyer-seller interactions. Psychology and Marketing, 12(4), 305-319.

Edworthy, J., \& Waring, H. (2006). The effects of music tempo and loudness level on treadmill exercise. Ergonomics, 49(15), 1597-1610.

Falkenstein, M., Hohnsbein, J., \& Hoormann, J. (1994). Time pressure effects on late components of the eventrelated potential (ERP). Journal of Psychophysiology, 8, 22-Fisher, J. D. (1974). Situation-specific variables as determinants of perceived environmental aesthetic quality and perceived crowdedness. Journal of Research in Personality, 8(2), 177-188.

Kaplan, Stephen (1987), "Aesthetics, Affect, and Cognition," Environment and Behavior, 19 (January), 3-32.

Kellaris, J. J., \& Kent, R. J. (1993). An exploratory investigation of responses elicited by music varying in tempo, tonality, and texture. Journal of Consumer Psychology, 2(4), 381-401.

Kelley NJ, Hortensius R, Schutter DJ, Harmon-Jones E. (2017). The relationship of approach/avoidance motivation and asymmetric frontal cortical activity: A review of studies manipulating frontal asymmetry. International Journal of Psychophysiology : Official Journal of the International Organization of Psychophysiology.

Kotler, P. (1973). Atmospherics as a marketing tool. Journal of Retailing 49(4), 48-64 
Mari \& Poggesi (2013) Servicescape cues and customer behavior: a systematic literature review and research agenda, The Service Industries Journal, 33:2, 171-199.

Lin, I.Y. (2010), "The interactive of Gestalt situations and arousal seeking tendency on customers' emotional responses: Matching color and music to specific servicescapes", Journal of Services Marketing, Vol. 24 No. 4, pp. 294-304.

Mari, M., \& Poggesi, S. (2013). Servicescape cues and customer behavior: a systematic literature review and research agenda. The Service Industries Journal, 33(2), 171-199.

Mattila, A. S., \& Wirtz, J. (2001). Congruence of scent and music as a driver of in-store evaluations and behavior. Journal of Retailing, 77(2), 273-289.

Mehrabian, A. \& Russell, J.A. (1974), An approach to environmental psychology, Cambridge, MA. : MIT Press.

Michel, Christoph M. and Micah M. Murray (2012). "Towards the utilization of EEG as a brain imaging tool”. In: NeuroImage 61.(2), pp. 371-385.

Milliman, Ronald (1982), "Using Background Music to Affect the Behavior of Supermarket Shoppers," Journal of Marketing, 46 (Summer), 86-91.

Milliman, Ronald (1986), "The Influence of Background Music on the Behavior of Restaurant Patrons," Journal of Consumer Re- search, 13 (September), 286-9.

Nasar, J. L. (1987). The Effect of Sign Complexity and Coherence on the Perceived Quality of Retail Scenes. Journal of the American Planning Association, 53(4), 499-509.

Oakes, S. (2000). The influence of the musicscape within service environments. Journal of Services Marketing, 14(7), 539-556.

Oliver, R.L. and Swan, J.E. (1989) Consumer Perceptions of Interpersonal Equity and Satisfaction in Transactions: A Field Survey Approach. Journal of Marketing, 53, 21.

Ramsøy,T.Z.(2014).Introduction to Neuromarketing and Consumer Neuroscience. Neurons Inc.

Rosen, D. E., \& Purinton, E. (2004). Website design: Viewing the web as a cognitive landscape. Journal of Business Research, 57, 787-794.

Schiffman, H. R. (2001). Sensation and perception (5th ed.). New York: Wiley..

Sweeney, J. C., \& Wyber, F. (2002). The role of cognitions and emotions in the music-approach-avoidance behavior relationship. Journal of Services Marketing, 16(1), 51-69.

Tollner, T., H. J. Muller, and M. Zehetleitner (2011a). "Top-down dimensional weight set determines the capture of visual attention: Evidence from the PCN component". In: Cerebral Cortex 22.(7), pp. 15541563.

Turley, L. ., \& Milliman, R. E. (2000). Atmospheric Effects on Shopping Behavior. Journal of Business Research, 49(2), 193-211.

Van der Lubbe, R. H., Jaśkowski, P., Wauschkuhn, B., \& Verleger, R. (2001). Influence of time pressure in a simple response task, a choice-by-location task, and the Simon task. Journal of Psychophysiology, 15(4), 241.

Van der Lubbe, R. H., \& Utzerath, C. (2013). Lateralized power spectra of the EEG as an index of visuospatial attention. Advances in cognitive psychology, 9(4), 184.

Vanderark, S. D., \& Ely, D. (1993). Cortisol, Biochemical, and Galvanic Skin Responses to Music Stimuli of Different Preference Values by College Students in Biology and Music. Perceptual and Motor Skills, 77(1), 227-234.

Vossel, S., J. J. Geng, and K. J. Friston (2015). Attention, predictions and expectations, and their violation: attentional control in the human brain. Frontiers Media SA. 